\title{
Erratum: Realizing long radio-frequency quadrupole accelerators with multiple shorter and independent cavities [Phys. Rev. Accel. Beams 23, 042003 (2020)]
}

\author{
Chuan Zhang ๑, Holger Podlech, and Eugene Tanke
}

(Received 1 September 2020; published 7 October 2020)

DOI: 10.1103/PhysRevAccelBeams.23.109901

In this paper, the citation of the IFMIF RFQ [1] (i.e., Ref. [8] in the original publication) as an example of using the "resonant coupling" approach was incorrect. Although the whole IFMIF RFQ has been divided into many mechanical modules (like the resonant coupling approach), no coupling cells were applied [2]. This paper presented a solution different from the resonant coupling approach as well as the approach adopted by the IFMIF RFQ. Furthermore, the IFMIF RFQ was not mentioned elsewhere in the text. Therefore, the removal of this reference to the IFMIF RFQ will have no influence on the content and the conclusions.

[1] E. Fagotti et al., Beam commissioning of the IFMIF EVEDA very high power RFQ, in Proceedings of IPAC2018 (JACoW, Vancouver, BC, Canada, 2018), p. 2902.

[2] A. Palmieri, F. Grespan, and A. Pisent, Tuning the IFMIF $5 \mathrm{MeV}$ RFQ accelerator, in Proceedings of LINAC2016 (JACoW, East Lansing, MI, USA, 2016), p. 969.

\footnotetext{
*.zhang@gsi.de
}

Published by the American Physical Society under the terms of the Creative Commons Attribution 4.0 International license. Further distribution of this work must maintain attribution to the author(s) and the published articles title, journal citation, and DOI. 